\title{
CIUDADANÍA E IDENTIDAD EUROPEA DESDE UNA PERSPECTIVA TRANSNACIONAL
}

\author{
Carlota Solé Puig * \\ Sònia Parella Rubio **
}

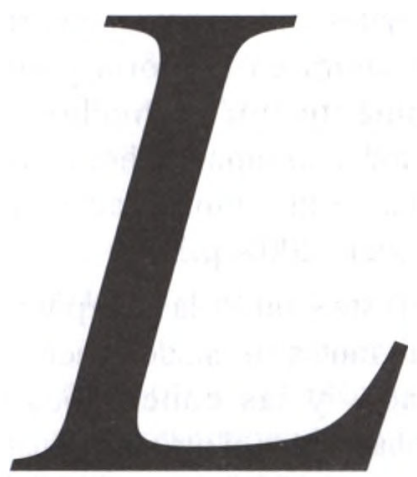

a consolidación de los procesos migratorios de carácter internacional y la llegada de personas que se asientan de forma más o menos permanente en las sociedades receptoras, plantea la necesidad de revisar la histórica relación entre el estado y la nacionalidad, una relación que cristaliza en la conformación de un estado-nación que "contiene" y da forma a la ciudadanía desde el siglo XIX en las sociedades occidentales. En otras palabras, se requiere reflexionar sobre cómo adecuar el modelo tradicional de ciudadanía a la nueva realidad. La actual coexistencia en nuestras sociedades de personas con diferentes sistemas de derechos y de deberes, por el simple hecho de poseer otra nacionalidad distinta, supone un gran desafío a la democracia (Zapata, 2000).

La función histórica del concepto de ciudadanía ha sido la de estructurar la sociedad, a partir de la creación de las lealtades necesarias para su estabilidad. De acuerdo con L. Suárez (2005), el concepto de ciudadanía centrado en el territorio no se adecua a las prácticas que los migrantes desarrollan, por cuanto éstas tienen lugar a través de vínculos transnacionales que ponen en cuestión el arraigado dogma de que los migrantes deben integrarse $y$ conseguir plenos derechos a partir de la naturalización y la renuncia a sus vínculos con el país de origen. Ante el requerimiento de diseñar una ciudadanía europea en el seno de la UE, debemos preguntarnos hasta qué punto es viable generar una identidad europea compartida a partir de una ciudadanía no inclusiva, fundamentada, por un lado, en la exclusión institucional -del derecho a voto, por ejemplo- de determinados colectivos que contribuyen activamente al crecimiento de estas sociedades (mediante el pago de impuestos, cotizaciones a la Seguridad Social, etc.); y, por el otro, anclada en el 
territorio de un estado-nación que ha dejado de ser el contenedor natural, dentro del cual transcurre la vida social, económica y política.

Por ello, este artículo pretende explorar distintas aproximaciones teóricas a la ciudadanía de residencia (ius domicilii) y se centra en una revisión del concepto de ciudadanía que, amparándose en una perspectiva transnacional, sea capaz de vehicularse a partir de una identidad europea compartida, compatible con las múltiples identidades (Brewer, 1999), pertenencias y prácticas colectivas de los ciudadanos en distintos espacios sociales y territoriales a la vez.

\section{LA NECESIDAD DE ADECUAR LA CIUdAdANía a LOS ESPACIOS SOCIALES “TRANSNACIONALES"}

Efectivamente, los vínculos de los migrantes con sus países de origen son más intensos ahora que en épocas anteriores. Los inmigrantes viven en "comunidades transnacionales" que comprenden, según Portes (1997, p.812), densas y tupidas redes a través de límites políticos creadas por los inmigrantes en busca del avance económico y el reconocimiento social. A través de estas redes, un creciente número de personas son capaces de vivir vidas duales en términos de lealtades. Sus integrantes son a menudo bilingües, se mueven con facilidad entre distintas culturas, frecuentemente mantienen un hogar en dos países y persiguen intereses políticos, económicos y culturales que requieren su presencia en ambos contextos. Dichas conexiones transnacionales permiten a los inmigrantes mantener identidades y prácticas colectivas en diversos espacios territoriales a la vez
(Vertovec, 2001). La multiplicidad de identidades, en constante redefinición y cambio, que definen los "espacios sociales transnacionales", pueden verse como no conflictivas, estructuradas a lo largo de la coexistencia de círculos concéntricos (Díez Medrano y Gutiérrez, 2001). Okamura (1981) propone, desde una perspectiva circunstancialista, el término "identidad situacional", para designar las identidades étnicas como situacionalmente maleables, dependientes del contexto, que son activadas dependiendo de la percepción subjetiva que el actor tenga de una situación dada, así como del grado en que éste perciba que la identidad es un factor relevante en dicha situación.

Las identidades múltiples y las redes transfronterizas de las comunidades migrantes transnacionales cuestionan la noción de que el estado-nación funciona como una especie de recipiente "contenedor" de procesos sociales, económicos y políticos. Los actores transnacionales ponen en entredicho la soberanía de los estados-naciones, lo que obliga a redefinir la relación entre las esferas nacionales y transnacionales (Vertovec, 2001). De acuerdo con Saskia Sassen (1998, p.52), uno de los rasgos definitorios de la globalización es que por el hecho de que determinados procesos sucedan dentro del territorio de un estado-nación, ello no significa que necesariamente sean nacionales. Los orígenes de la perspectiva transnacional en el estudio de las migraciones son, en gran medida, una reacción ante la insatisfacción de las teorías predominantes sobre migración hasta la década de los ochenta, por cuanto éstas ponían un acento excesivo en los aspectos económicos y en la inexorabilidad de la asimilación unidireccional de los migrantes a la sociedad receptora después de un par de generaciones, con la consiguiente ruptura de sus vínculos con el país de origen (Castro, 2005; Le Gall, 2005).

El estudio de las migraciones desde una perspectiva transnacional proporciona un nuevo marco analítico que hace visible la creciente intensidad de los flujos poliédricos de personas, objetos, información y símbolos y permite analizar cómo los migrantes construyen y reconstruyen sus vidas, simultáneamente imbricadas en más de una sociedad (Caglar, 2001). Abordar las migraciones internacionales desde la perspectiva transnacional requiere superar el "nacionalismo metodológico"; a saber, la asunción de que el estado-nación es el contenedor natural y lógico dentro del cual transcurre la vida social. El hecho de que los "espacios sociales transnacionales" no se hayan incorporado hasta ahora en la teoría política es justamente por el hecho de que cuestionan la supuesta homogeneidad interna de las comunidades políticas (Bauböck, 2004, p.183).

En este sentido, la incorporación de los migrantes en estados-naciones, por un lado, y las conexiones transnacionales, por el otro, no constituyen procesos sociales contradictorios (Levitt y Glick Schiller, 2004). Lejos de ser así, la presencia de los inmigrantes en una nueva sociedad y las conexiones trasnacionales de carácter económico, afectivo o político con la tierra de origen -o bien con redes dispersas que tienen que ver con la familia, los connacionales o con personas con las que se comparte una religión o una identidad étnica- pueden darse a la vez y son procesos que se refuerzan mutuamente. En este sentido, la simultaneidad del hecho de incorporarse a actividades, rutinas e instituciones localizadas tanto en el 
país de destino como en el de origen es una realidad.

Las afiliaciones políticas a estados independientes no son mutuamente incompatibles. De acuerdo con Bauböck (2004, p.195), “desde una perspectiva transnacional, la inmigración conecta a las sociedades de origen y receptoras, no sólo a través de los flujos económicos y el intercambio cultural, sino generando límites solapados de pertenencia. Esta condición de pertenecer simultáneamente a dos sociedades organizadas como estados independientes se refleja en las experiencias subjetivas de inmigrantes y crea oportunidades, aunque también cargas". En este sentido, de acuerdo con los pronósticos de S. Castles (2004, p.48), las afiliaciones transnacionales serán la forma predominante de pertenencia inmigrante en el futuro. Lo que queda pendiente es establecer bajo qué criterios jurídicos y políticos podrán regularse y canalizarse estos tipos de pertenencia.

Dentro de los espacios sociales transnacionales, los intereses de los migrantes como ciudadanos se vinculan con otras personas y colectivos no necesariamente en base a su pertenencia a un grupo nacional, sino por su identificación con un grupo religioso, un determinado grupo étnico, un grupo de interés económico, o bien un grupo vecinal (Suárez, 2005). Se trata de afiliaciones compatibles que, en la mayoría de las ocasiones, de acuerdo con L. Suárez (2005), coexisten con un sistema de identidades múltiples que se solapan y a menudo se contradicen. Beck (2005) desarrolla las lógicas de la identidad a partir de la contraposición entre la identidad tradicional, basada en una dinámica excluyente ("soy esto, luego no soy lo otro"), y la cosmopolita, construida sobre una lógica incluyente ("soy no sólo esto, sino esto otro también").

Los vínculos sociales y simbólicos que tejen los espacios sociales transnacionales pueden asumir una forma más institucional a través de la ciudadanía, por cuanto ésta regula los vínculos entre ciudadanos y estados a través de la ley. En el contexto de la era de la "globalización", de acuerdo con Faist (2004, p.4), se asiste a un cambio de orientación que supone abandonar las políticas orientadas hacia el estado y dar paso a.un tipo de governanza (governance) más compleja, global y multi-nivel. La UE constituye un claro ejemplo de dicho fenómeno. Sin embargo, el proyecto de construcción de la UE no ha tenido suficientemente en cuenta otra de las caras de los espacios sociales transnacionales: las migraciones internacionales, sus dinámicas y el consiguiente asentamiento de minorías étnicas en los países europeos. La cuestión de los "derechos de ciudadanía” y su reconceptualización en el contexto de la "Nueva Europa" está generando importantes elementos de reflexión que, según Solomos (1994:45), se centran principalmente en, por un lado, los derechos culturales y religiosos de las minorías en sociedades cada vez más diversas y, por el otro, la cuestión de los derechos políticos de los migrantes y la extensión de las nociones de ciudadanía y democracia, el eje estructurador de este artículo.

En lo que concierne a los derechos políticos, los transmigrantes despiertan reticencias a la hora de conceder los mismos. De acuerdo con Castles (2004), si bien la figura del transmigrante se asocia al cosmopolitismo, así como a la capacidad de trascender las fronteras culturales y de construir identidades múltiples o híbridas, muchas veces la conciencia transnacional se basa en la etnicidad común, en la solidaridad hacia los coétnicos en la tierra natal o en cualquier otro lugar del mundo. El caso de la comunidad cubanoamericana en el Sur de Florida, por ejemplo, muestra cómo una comunidad puede tener capacidad económica y política para movilizar su potencial de votantes cubanoamericanos e influir en la política del país receptor hacia su país de origenel régimen castrista-. Es lo que se conoce como "nacionalismo de diáspora" (Bauböck 2004). Esta visión contribuye a percibir muchas veces las comunidades transnacionales como amenaza, por cuanto pueden ser consideradas la base del fundamentalismo y la subversión. Sin embargo, en la práctica la mayor parte de los miembros se sitúan entre estos extremos, con identidades a la vez contradictorias y fluctuantes, con consciencia tanto transnacional como étnica, a las que autores como R. Kastoryano (1998) denominan "identidad negociada".

De acuerdo con J. de Lucas (2004), la presencia de inmigrantes cuestiona la conexión entre nacimiento, territorio y estado, base de la soberanía moderna desde la declaración de los Derechos del Hombre de 1789. Si, de acuerdo con R. Baübock (2004), definimos la ciudadanía como aquel estatus de completa e igualitaria pertenencia a una comunidad política con autogobierno, que comporta derechos y obligaciones, el quid de la cuestión se encuentra en resolver qué derechos y obligaciones pueden asignar los estados a sus inmigrantes sin interferir en la soberanía territorial del estado anfitrión. Muchos países receptores de inmigración conceden determinados derechos civiles, económicos o sociales a los extranjeros, aunque no 
posean el título de ciudadanía, si bien dicha concesión y el tiempo de residencia exigido para la misma varía de un país a otro (Zincone, 2004, p.239). Incluso los inmigrantes no regularizados reciben de hecho, pese a las legislaciones cada vez más restrictivas, prestaciones educativas y sanitarias o de otro tipo. Por consiguiente, si se asume que el reconocimiento de los derechos humanos no necesariamente debe estar unido al estatuto de ciudadanía -al menos mientras éste se mantenga vinculado al título de nacionalidad-, ¿bajo qué criterio se niega a los inmigrantes con determinados requisitos el conjunto de derechos políticos?

Puesto que los factores que conducen a la formación y mantenimiento de los espacios sociales transnacionales -medios tecnológicos de comunicación, formación de incompletos estados-naciones en muchos países de emigración, discriminación y multiculturalismo en los países de inmigración, etc.- van a seguir expandiéndose, el actual modelo de ciudadanía estado-nación ya no es adecuado. Según S. Castles (2004, p. 49), en un mundo en que los flujos están sustituyendo a los lugares como punto clave de organización económica y social y en que las personas se mueven a menudo entre distintos países y mantienen distintas afiliaciones con todos estos lugares, la ciudadanía necesita adaptarse a las nuevas realidades".

Todo ello obliga a repensar el concepto de ciudadanía desde la "extraterritorialidad". La práctica de la ciudadanía sitúa al individuo, el ciudadano de la UE, ante múltiples pertenencias y lealtades que suponen una variación del estado-nación unitario y territorial (Kastoryano, 1998). Hasta el momento, los estados- naciones no prevén ninguna otra posibilidad de alcanzar el estatuto de ciudadanía que no sea el de la "naturalización", lo que conlleva asumir que la asimilación cultural es la precondición para la integración política. Sin embargo, sí es posible abogar por otros tipos de ciudadanía, que sean compatibles con la pluralidad de pertenencias nacionales y que van a ser desarrollados en el siguiente apartado.

\section{LOS RETOS ANTE LA CONSTRUCCIÓN DE UNA CIUDADANÍA EUROPEA}

Crear una identidad europea tras el auge de los estados-naciones y la importancia de la identidad nacional en su seno -amén de los conflictos identitarios de las naciones dentro de los estados-, se plantea actualmente en nuevos términos ante la presencia de la inmigración extracomunitaria con proyectos de permanencia. La identidad europea, con la consolidación de la unidad política y administrativa que puede llegar a ser la Unión Europea, diluye por un lado las fronteras entre los estados europeos, pero, por el otro, difumina también el sistema de valores común y subyacente a estos estados, apoyados en una nación, a veces de creación estatista, pero comulgando de la tradición judeo-cristiana en sus preceptos y normas básicos (Solé y Parella, 2006).

La creación de la Unión Europea conlleva la aparición de eurociudadanos pertenecientes a una unidad política supra-estatal, administrativamente hablando, pero que carecen todavía de identidad como ciudadanos de esa unidad política. La gran mayoría de europeos comparten las creencias, valores y normas de la tradición judeo-cristiana, así como la confianza en los instrumentos jurídicopolíticos para crear las instituciones pertinentes para lograr una convivencia harmónica y cohesionada socialmente. La pregunta que cabe formularse es si puede haber universalidad de los valores occidentales, de modo que puedan ser aceptados y adaptados por personas de otras creencias religiosas y culturales, minimizando los conflictos entre comunidades culturales distintas y los riesgos de defección o abandono por unos respecto a los otros .

De acuerdo con Solé y Parella (2006), la integración de los inmigrantes en sociedades capitalistas y democráticas, va a permitir realzar el papel de los intereses sobre los valores a la hora de definir la nueva identidad europea, porque al relativismo de los valores se impone el universalismo de los intereses. En este sentido, son los intereses (económicos, políticos, etc.) y las experiencias históricas los que constituyen la base de la nueva unidad política sobre la cual deberá construirse la identidad europea. La construcción de una ciudadanía europea supranacional y a la vez transnacional implica explicitar las condiciones de pertenencia y los intereses objetivos de los inmigrantes. Los inmigrantes residentes en diversos países de la UE, entre ellos España, más allá de sus múltiples afiliaciones, perseguirán el objetivo común de mejorar sus condiciones de vida. Los individuos tienen sobre todo intereses que derivan de su situación en el proceso y estructura productivos y, en consecuencia, de su posición social (Dahrendorf, 1959). En este sentido, los inmigrantes van a desarrollar intereses comunes por el hecho de compartir circunstancias y hechos, tales como su situación de precariedad 
y discriminación en el mercado de trabajo, la marginación social o la no participación política. Estos hechos y circunstancias marcan la interacción (relación) entre ellos y los autóctonos.

La construcción de una ciudadanía supranacional en la Unión Europea, con la presencia creciente de inmigración con distintas culturas, religiones y tradiciones convivenciales y de gestión de la vida pública, plantea la cuestión de cuáles son los intereses que pueden ser comunes a los autóctonos europeos y a los inmigrantes, para permitir generar una identidad europea. Los intereses comunes pueden convertirse en intereses colectivos en la medida en que no sólo convergen los actores sociales en el propósito de alcanzar el mismo objetivo, sino que actúan cooperando en pro del "bien social" no material, intangible y simbólico que representa la ciudadanía. La producción de este bien social requiere la acción conjunta de los individuos que no tienen otra opción que cooperar para conseguirlo. La acción colectiva que se emprende va a derivar en la producción de solidaridad de grupo, lo que a su vez refuerza el desarrollo de una identidad colectiva (Hechter, 1987). Así pues, es la percepción de intereses comunes la que conduce al desarrollo de una identidad colectiva que, recíprocamente, hace posible la consecución de dichos intereses (Tilly, 1978).

En este proceso, unos y otros, inmigrantes y autóctonos, cederán parte de sus anteriores haberes o, incluso, privilegios; con el fin de lograr la conjunción y convergencia de intereses, compartir una identidad y perseguir y optar por unos beneficios materiales y simbólicos. Intentar superar la situación objetiva de desventaja respecto a los autóctonos induce a los inmigrantes a desear alcanzar la condición de ciudadanos. Los autóctonos, por su parte, admitirán esta posibilidad en la medida que sus intereses económicos (acceso al mercado de trabajo y a las prestaciones sociales del Estado del bienestar), políticos y culturales se cubran.

Somos conscientes de los riesgos que entraña, en términos de sentimiento de "amenaza" y de "competencia" por parte de los autóctonos, la ampliación de la base de participación política con la concesión del derecho a voto a los residentes extranjeros. En este sentido, la superación de las desigualdades en base a la etnia o a la condición jurídica o social de inmigrante es fundamental para superar las objeciones que la concesión de derechos políticos a los residentes extranjeros genera entre los autóctonos. A corto plazo, debe evitarse que los intereses específicos de los inmigrantes, derivados de su posición desigual en la estructura social, promuevan la creación de sindicatos o partidos políticos étnicos (así como facciones étnicas dentro de los sindicatos o los partidos políticos generales), con el riesgo de acentuar todavía más la fractura social.

Por ello, sólo una estructura social menos rígida y menos segmentada, con políticas sociales diseñadas desde una lógica universalista y no asistencial, así como con ausencia de discriminación racial y étnica, reducirá el riesgo de divisiones étnicas de las instituciones (sindicatos, partidos políticos...). Además, favorecerá que los autóctonos perciban en mayor medida que los inmigrantes no persiguen proyectos sólo parciales, sino también comunes y colectivos; lo que va a reducir el conflicto de intereses entre ambos colectivos (Solé y Parella, 2003). Es, precisamente, a través de la integración de los inmigrantes en la estructura ocupacional y social que obtendrán el reconocimiento como miembros del grupo. A partir de este reconocimiento desarrollarán estrategias racionales para actuar en la consecución de nuevos intereses, tanto propios (representación política como grupo étnico, por ejemplo) como comunes y compartidos con los autóctonos.

\section{CONCLUSIONES}

El juego de identidades múltiples que acompaña a los espacios sociales transnacionales se transforma en poliédrico en el nuevo contexto jurídico y político, supra-estatal y diverso culturalmente. ¿Cómo puede la Unión Europea lograr un estado supranacional europeo y una identidad europea compartida? Por un lado, se requiere una cultura política común, reflejada en una Constitución democrática europea hacia la que los ciudadanos sientan lealtad. Por el otro, la identidad europea del futuro debería girar en torno al reconocimiento de la ciudadanía para todos y todas y a una fuerza descentralizadora y flexible que permita lealtades intermedias y múltiples, que reconozca la diversidad cultural y permita mantener los vínculos simultáneos con el lugar de origen (los espacios sociales transnacionales). De esta manera, todo ciudadano europeo dispondría de otros polos de identidad afianzados en los niveles étnico, lingüístico, histórico y local, con afiliaciones diversas y orientadas tanto hacia el país de origen como hacia el país de destino -para el caso de los migrantes-, compatibles con un sentimiento de pertenencia a la comunidad política europea (Solé y Parella, 2003).

En definitiva, los inmigrantes tendrán incentivos para materializar su vínculo con las sociedades europeas a 
medida que se percaten de que existen posibilidades de movilidad ocupacional y social, y de que son partícipes del crecimiento económico y social que ellos contribuyen directamente a generar, a través de los canales de participación política. Todo ello, sin que dicha concepción de la "ciudadanía" suponga tener que "asimilarse" o renunciar a sus identidades de origen, sino integrarse en pie de igualdad, en calidad de ciudadanos plenos, con el resto de la población. En definitiva, se trata de compartir una cultura política de dominio público (basada en la igualdad de oportunidades, en los valores democráticos y en la ausencia de discriminación racial y étnica), que permita a las personas de origen inmigrante actuar como sujetos activos que participan conflictual y estratégicamente en la construcción de la sociedad en la que residen. Todo ello teniendo además en cuenta el contexto de transnacionalismo en el que operan los inmigrantes -tanto a nivel de intereses, prácticas, identidades como de afiliaciones políticas-, así como la realidad cada vez más compleja de la nueva Europa como sociedad global.

* Carlota Solé Puig Catedrática Dpto. Sociología - UAB, Directora del GEDIME (Grup d'Estudis sobre Immigració $i$ Minories Ètniques).

* Sònia Parella Rubio Profesora Lectora Dpto. Sociologia - UAB, Investigadora del GEDIME.

\section{REFERENCIAS BIBLIOGRÁFICAS}

BAUBÖCK, R.

(2004) "Cómo transformar la inmigración a la ciudadanía: perspectivas internacionales, multinacionales y transnacionales". En: AUBARELL, G. y ZAPATA, R. (eds.). Inmigación y procesos de cambio. Barcelona, Icaria, pp. 177214.
BECK, U.

(2005) La mirada cosmopolita o la guerra es paz. Barcelona, Paidós.

BREWER, M. B.

(1999) "Multiple Identities and Identity Transition: Implications for HongKong". International Journal of Intercultural Relations, $\mathrm{n}^{\circ}$ 23, pp. 187197.

CAGLAR, A.

(2001) "Constraining metaphors and the transnationalisation of spaces in Berlin". Journal of Ethnic and Migration Studies, no. 27, vol. 4, pp. 601-613.

CASTLES, S.

(2004) "Globalización e inmigración”. En: Aubarell, G. y ZAPATA, R. (eds.) Inmigación y procesos de cambio. Barcelona, Icaria, pp. 33-56.

CASTRO, Y.

(2005) "Teoría transnacional: revisitando la comunidad de los antropólogos”. Política y Cultura, nำ23, pp. 181-194.

DAHRENDORF, $R$.

(1959) Class and Class Conflict in Industrial Society. Stanford (CA), Stanford University Press.

DÍEZ MEDRANO, J. y GUTIÉRREZ, P. (2001) "Nested identities: national and European identity in Spain". Ethnic and Racial Studies, vol. 24, no 5, pp. 753778.

FAIST, Th.

(2004) "The Border-Crossing Expansion of Social Space: Concepts, Questions and Topics". En: FAIST, Th. y ÖZVEREN, E. (eds.) Transnational Social Spaces. Aldershot, Ashgate, pp. 1-34.

HECHTER, M.

(1987) Principles of Group Solidarity. Berkeley (CA), University of California Press.

KASTORYANO, R.

(1998). "Transnational Participation and Citizenship. Immigrants in the European Union". Working Paper Transnational Communities 98-12. [http://www.transcomm.ox.ac.uk/ working\%20papers/riva.pdf]

LE GALL, J.

(2005) "Familles transnationales: bilan des recherches et nouvelles perspectives". Diversité urbaine, vol. 1, n으, pp. 29-42.

LEVITT, P.; GLICK SCHILLER, N.
(2004) "Transnational perspectives on migration: conceptualizing simultaneity". International Migration Review, n 38, pp. 1002-1040.

LUCAS, J. de

(2004) "Ciudadanía: la jaula de hierro para la integración de los inmigrantes". En: AUBARELL, G. y ZAPATA, R. (eds.). Inmigación y procesos de cambio. Barcelona, Icaria, pp. 215236.

OKAMURA, J. Y.

(1981) "Situational ethnicity". Ethnic and Racial Studies, vol. 4, n 4, pp. 452-465.

PORTES, A.

(1997) "Immigration theory for a new century: Some problems and opportunities". International Migration Review, n 31, pp. 799-825.

SASSEN, S.

(1998) "The de facto transnationalizing of immigration policy". En: JOPPKE, C. (ed.) Challenge to the Nation-State: Immigration in Western Europe and the United Status. Oxford, Oxford University Press, pp. 49-85.

SOLÉ, C. y PARELLA, S.

(2003) "Identidad colectiva y ciudadanía supranacional". Papeles de Economía Española, nº 98, pp. 166181.

SOLÉ, C. y PARELLA, S.

(2006) "Intereses e identidad". Praxis Sociológica, $n^{\circ}$ 9, pp. 9-22.

SOLOMOS, J.

(1994) "The Politics of Citizenship and Nationality in a European Perspective". En: MARTINIELLO, M. (ed.) Migration, Citizenship and Ethno-National Identities in the European Union. Aldershot, Ashgate, pp. 40-52.

SUÁREZ, L.

(2005) "Ciudadanía y migración: ¿un oxímoron?". Puntos de Vista, $n^{\circ} 4, \mathrm{pp}$. 29-47.

TILLY, C.

(1978) From Mobilization to Revolution. Reading (MA), AddisonWesley Publishing Company.

VERTOVEC, S.

(2001). "Transnational Challenges to the 'New' Multiculturalism". Papel presentado en ASA Conference, celebrada en la University of Sussex, 30 marzo -2 Abril 2001.

ZAPATA, $R$.

(2000) “Inmigración e innovación política”. Migraciones, nº 8, pp. 7-58. 